\title{
Knowledge, Attitude and Practice of Elderly Outpatients with Type 2 Diabetes Mellitus in National Geriatric Hospital, Vietnam
}

This article was published in the following Dove Press journal:
Diabetes, Metabolic Syndrome and Obesity: Targets and Therapy

\author{
Anh Trung Nguyen, 1,2 \\ Hai Quang Pham, 3,4 \\ Thanh Xuan Nguyen, (D) 1,2,5 \\ Thu Thi Hoai Nguyen, (D) ${ }^{1,2}$ \\ Huong Thi Thu Nguyen, (iD 1,2 \\ Tam Ngoc Nguyen, (ID) ${ }^{1,2}$ \\ Dung Thi Kim Dinh,' \\ Hai Thanh Phan, 3 \\ Son Hoang Nguyen, ${ }^{6}$ \\ Bach Xuan Tran, 7,8 \\ Carl A Latkin, (D) ${ }^{8}$ \\ Roger CM Ho, (iD) 9,10 \\ Cyrus SH Ho, (iD ${ }^{9}$ Thang Pham, ${ }^{1,2}$ \\ Huyen Thi Thanh Vu (D) ${ }^{1,2}$

\begin{abstract}
'Hanoi Medical University, Hanoi, Vietnam;
${ }^{2}$ National Geriatric Hospital, Hanoi, Vietnam;

${ }^{3}$ Institute for Global Health Innovations, Duy

Tan University, Da Nang, Vietnam; ${ }^{4}$ Faculty of

Vietnam; ${ }^{5}$ Dinh Tien Hoang Institute of

Medicine, Hanoi, Vietnam; ${ }^{6}$ Center of

Excellence in Health Services and System

Chi Minh, Vietnam; ${ }^{7}$ Institute for Preventive

Medicine and Public Health, Hanoi Medical

University, Hanoi 100000, Vietnam;

${ }^{8}$ Bloomberg School of Public Health, Johns

Hopkins University, Baltimore, MD, USA;

${ }^{9}$ Department of Psychological Medicine, Yong

Loo Lin School of Medicine, National

University of Singapore, Singapore, Singapore;

${ }^{10}$ Institute for Health Innovation and

Technology (iHealthtech), National University
\end{abstract} \\ Medicine, Duy Tan University, Da Nang 550000, \\ Research, Nguyen Tat Thanh University, Ho \\ of Singapore, Singapore, Singapore
}

Correspondence: Huyen Thi Thanh Vu Department of Geriatrics, Hanoi Medical University, 0I Ton That Tung, Hanoi, Vietnam

Tel +84913531579

Email vuthanhhuyenII@hmu.edu.vn
Background: Diabetes-related complications have become increasingly prevalent and complicated to manage, especially among frail older adults with co-morbidities, poor physical function, and impaired cognition. Thus, knowledge, attitude, and practice (KAP) of elderly diabetic patients play an essential role in controlling the disease and its complications.

Patients and Methods: A cross-sectional study was conducted on 176 diabetic patients at the outpatient clinics, National Geriatric Hospital, Hanoi, Vietnam from August to November 2015. Patients' knowledge, attitude, and practice regarding diabetes mellitus were assessed using a structured questionnaire. Exploratory factor analysis and multivariate Tobit regression model were used to identify factors associated with knowledge, attitude, practice about diabetes mellitus.

Results: Of 176 diabetic patients, patients' knowledge was divided into two main groups: "Diabetes definition and management" (mean score $=57.7 \pm 25.6$ ) and "Targets for diabetic control" (mean score $=66.1 \pm 30.4$ ). Patients scored high points of attitudes toward diabetes severity and its complications (mean score $=95.8 \pm 13.0$ ); however, knowledge and practice scores were only moderate (mean score $=68.1 \pm 16.8$ ). There were only $8.5 \%$ of people having daily self-blood glucose monitoring. Advanced age, low educational level, rural area, and duration of diabetes less than 5 years were negative associated with knowledge, attitude, and practice regarding diabetes mellitus. This study also shows that frailty and comorbidities/diabetic complications could impair patients' knowledge.

Conclusion: Older patients with diabetes had high levels of perceived severity attitudes on diabetes mellitus. However, the knowledge and practice levels were still inadequate. Pragmatic diabetic health literacy, counseling and education programs, as well as homebased treatments are viable options to improve health outcomes.

Keywords: attitude, diabetes, elderly, knowledge, practice

\section{Introduction}

Type 2 diabetes has been dramatically prevalent across nations. According to the International Diabetes Federation (IDF) 2019, 463 million adults are currently living with diabetes, of which, approximately 20\% (136 million) people are 65 years old and over. IDF estimates that there will be 578 million adults with diabetes by 2030 , and 700 million by 2045 . In the South-East Asia region, there were approximately 87.6 million people suffering from diabetes in 2019, and it is projected to increase by up to 152.8 million people in 2045. IDF also predicted that the number of people older than 60 years with diabetes will double in the next 
50 years due to population aging. In line with the global trend, the estimated prevalence of diabetes in Vietnam will rise from $8.8 \%$ in 2019 to $11.3 \%$ in 2045 . $^{1}$

Diabetes Mellitus (DM) and its complications negatively impact the quality of life of elderly patients and increase healthcare costs. ${ }^{2,3}$ It has been noted that older patients are at higher risk of severe diabetes-related complications such as the highest rates of major lowerextremity amputation, myocardial infarction, visual impairment, and end-stage renal disease of any age group; therefore, attention should be paid to the management of diabetes and its complications in the elderly population. ${ }^{4,5}$ In order to control diabetes and prevent its chronic complications, self-care habits (the use of diabetic medication, implement healthy lifestyles: balanced diet, regular exercise, quit smoking and alcohol) play a critical role. However, functional impairment and dependence among older adults is a barrier to self-care. Previous studies indicated that DM self-care among older patients has better long-term glycemic control, functionality, and lifestyle through improved knowledge and attitude about the disease. ${ }^{6,7}$ Knowledge, attitude, and practice (KAP) regarding diabetes have been demonstrated to have an essential role to ensure better management of the disease. ${ }^{8}$ KAP data can be critical to building health promotion and public health responses. ${ }^{9}$ They can provide policymakers, planners, and health system managers crucial detailed information, particularly when the availability of administrative data is limited. ${ }^{10}$

Vietnam has one of the fastest rates of aging in the world, and the diabetic prevalence in Vietnam has progressively increased with advancing age. ${ }^{11,12}$ Despite the high prevalence of DM among Vietnamese adults, patients often lack their knowledge and skills to manage the disease. A study in the Red River Delta showed a low level of knowledge about diabetes among the general population aged 40-64 years old. ${ }^{13}$ However, in Vietnam, there is a scarcity of studies as well as survey instruments regarding KAP on diabetes among diabetic patients, especially in older populations. The National Geriatric Hospital (NGH), which is the leading hospital in Vietnam that provides care for older patients, started the national program on older diabetic management in 2005. Patients referred to NGH for diabetic diagnose and management are requested to visit every month for checkup and medicine dispensing, which is covered by medical insurance. The present study aimed to describe the knowledge, attitude, and practice of diabetic management, preventing diabetic complications, and identify related factors affecting KAP among elderly outpatients in National Geriatric Hospital. The research is expected to provide insights to improve the treatment and management of diabetes in the elderly.

\section{Patients and Methods Study Design and Participants}

A cross-sectional study was conducted from August to November 2015 at the Out-patient Department, National Geriatric Hospital. We included patients 60 years old and over, diagnosed with type $2 \mathrm{DM}$, according to the diagnostic criteria of the International Diabetes Federation 2013. ${ }^{14,15}$ All patients were examined, monitored, and treated at outpatient clinics of the National Geriatric Hospital. We excluded the patients unable to complete the questionnaire or communicate (including those with severe medical conditions, mental disorders, or cognitive impairment). The formula $\left[z^{2} p(100-p) / d^{2}\right]$ was used in the sample calculation, with an alpha error of $5 \%(\mathrm{z})$, a prevalence of good levels of knowledge about diabetes, and a positive attitude and practice of $50 \%$ (p), with an $8 \%$ error margin (d). To compensate for the patients who might not answer the questionnaire completely or may end up refusing to participate, an additional $15 \%$ was added to the sample size. The resulting minimum sample size was 173 older diabetic patients. Patients were randomly selected until the appropriate sample size was reached (16 patients refused to participate in the study). Finally, data from a total of 176 patients completing the questionnaire were used for analysis.

\section{Data Collection and Definitions}

The study was approved by the National Geriatric Hospital Research Ethics Committee. Written informed consent was obtained from each patient at the time of their visit to the hospital. Data were collected by three well-trained nurses: one was a nurse at the National Geriatric Hospital and two other ones were advanced nursing students at Hanoi Medical University. They all had research experience in geriatrics. To ensure consistency in the data collection process, all nurses underwent a training session on survey administration. Clinical data, including diabetes complications and current medication of participants, were retrieved from medical records.

\section{The Instrument}

Participants were interviewed to assess knowledge, attitude, and practice on general diabetes, diabetes management, and 
related complications using a standardized questionnaire, which was adapted from the Diabetes Knowledge Test (DKT) and Diabetes Attitude Survey (DAS). ${ }^{16,17}$ A standardized process was applied for developing the Vietnamese version of the questionnaire to use in the study. This includes the following steps: First, we conducted a forward-backward translation from English into Vietnamese involving an English translator, geriatricians, endocrinologist, and representative of the patients. Any discordance that emerged from the translation was reviewed and discussed among the team. Secondly, we piloted the instrument among a small sample of 20 patients. This pilot was to 1) assess the feasibility of using the translated tool among this patient group including administered methods, time, flow, and 2) an assessment of patients' responses to understand if any factors may affect the validity of the instrument. Finally, we conduct a post-pilot review among the research team to finalize the Vietnamese version of the questionnaire.

The first part of the questionnaire covered the demographic information that included age, gender, level of education, living area, diabetic duration, co-morbidities, and ability to pay hospital fees. A reduced level of exercise was assessed by self-reporting of the patients' ability to do heavy housework, walk up or downstairs without help.

Patients' knowledge about diabetes was assessed by 11 multiple choice questions which were divided into two parts: knowledge of diabetes including the definition and management (seven questions: DM definition, long-term damage of diabetes, causes and risk factors, the benefit of exercise, periodic measuring glycosylated hemoglobin, the best way to take care of diabetic patients' feet, good diet for diabetic patients). The second part was knowledge of targets for diabetic control, assessed by four questions whether the patients knew the goal index of fasting plasma glucose, postprandial glucose, blood pressure, and total cholesterol.

Patients' attitude toward DM severity was assessed by nine questions: exercise, diet, blood glucose, weight control, medication, the impact of DM in patients' life, cost of treatment, regular health checks, and family support. The final part covered the patients' practice on diabetes (8 questions): how frequently the patients perform self-management to prevent DM complications: quit smoking, regular selfblood glucose monitoring, blood pressure, exercise, medication, diet, eye-check, and actively seek or request medical services to have periodically blood lipid testing in the last year.
Each correct response was scored as 1 point, incorrect/ unknown response was scored as 0 . The total score was calculated by adding up all the points, higher scores indicating greater knowledge, attitudes and practices among patients. The conversion into a 100 range score was applied to the total score of knowledge, attitudes and practices. We calculated by multiplying the average score of each domain to 100 .

Frailty syndrome was defined using the Fried criteria. The Fried frailty phenotype included five criteria: patients who met at least three criteria were considered to be frail, whereas those with one or two criteria were pre-frail, and those with no characteristics were defined as robust. ${ }^{18}$

\section{Statistical Analysis}

We used Stata software version 15.0 to analyze the data. Descriptive statistics were used to present demographic information and KAP scores of the study population. We used exploratory factor analysis (EFA) to explore the construct validity of the questionnaire measuring the knowledge of respondents in terms of DM. An eigenvalue of 1.0, where its curve flattened out, was selected as a threshold. We used Orthogonal Varimax rotation with Kaisers' normalization to increase the interpretability of these factors. A value of 0.5 was utilized to be a cut-off point for factor loadings. Cronbach's alpha was used to assess the internal consistency reliability of measurement. Multivariable Tobit regression - censored regression model - was used to identify factors related to KAP score, forward stepwise selection was applied to develop the final model that only contains variables having a p-value at the log-likelihood ratio test less than 0.2 . Statistical significance was defined as any p-value less than 0.05 .

\section{Results}

A total of 176 patients with diabetes were enrolled in this study. The female to male ratio was 1.51 , and most of them lived in urban areas (93.8\%), 50.6\% of the patients had diabetes for a duration of more than 10 years, $18.8 \%$ of patients had frailty syndrome. The most prevalent comorbidity was hypertension (76.1\%), followed by dyslipidemia (60.2) and musculoskeletal diseases (38.1\%) (Table 1).

Table 2 shows the results of exploratory factor analysis for knowledge about diabetes. There are two domains of knowledge about diabetes among patients: "Diabetes definition and management" and "Targets for diabetic control". Cronbach's alpha indexes of these domains were 0.67 and 0.64 , respectively. The average score for the 
Table I Socio-Economic Status and Health Status of Respondents

\begin{tabular}{|c|c|c|c|c|c|c|c|}
\hline \multirow[t]{2}{*}{ Characteristics } & \multicolumn{2}{|c|}{ Male } & \multicolumn{2}{|c|}{ Female } & \multicolumn{2}{|c|}{ Total } & \multirow[t]{2}{*}{ p-value } \\
\hline & $\mathbf{n}$ & $\%$ & $\mathbf{n}$ & $\%$ & $\mathbf{n}$ & $\%$ & \\
\hline Total & 70 & 39.8 & 106 & 60.2 & 176 & 100 & \\
\hline \multicolumn{8}{|l|}{ Age group } \\
\hline $60-69$ & 38 & 54.3 & 54 & 50.9 & 92 & 52.3 & 0.66 \\
\hline$\geq 70$ & 32 & 45.7 & 52 & 49.1 & 84 & 47.7 & \\
\hline \multicolumn{8}{|l|}{ Living area } \\
\hline Urban & 64 & 91.4 & 101 & 95.3 & 165 & 93.8 & 0.30 \\
\hline Rural & 6 & 8.6 & 5 & 4.7 & 11 & 6.3 & \\
\hline \multicolumn{8}{|l|}{ Education level } \\
\hline Lower than High school & 19 & 27.1 & 38 & 35.9 & 57 & 32.4 & 0.04 \\
\hline High school & 21 & 30.0 & 41 & 38.7 & 62 & 35.2 & \\
\hline Higher than High school & 30 & 42.9 & 27 & 25.5 & 57 & 32.4 & \\
\hline \multicolumn{8}{|l|}{ Diabetes duration } \\
\hline Under 5 years & 17 & 24.3 & 26 & 24.5 & 43 & 24.4 & 0.84 \\
\hline $5-10$ years & 16 & 22.9 & 28 & 26.4 & 44 & 25.0 & \\
\hline Over 10 years & 37 & 52.9 & 52 & 49.1 & 89 & 50.6 & \\
\hline Able to pay for diabetic treatment & 59 & 84.3 & 79 & 74.5 & 138 & 78.4 & 0.12 \\
\hline \multicolumn{8}{|l|}{ Co-morbidity } \\
\hline None & 9 & 12.9 & 8 & 7.6 & 17 & 9.7 & 0.09 \\
\hline I disease & 15 & 21.4 & 14 & 13.2 & 29 & 16.5 & \\
\hline 2 diseases & 19 & 27.1 & 20 & 18.9 & 39 & 22.2 & \\
\hline 3 diseases & 16 & 22.9 & 39 & 36.8 & 55 & 31.3 & \\
\hline$\geq 4$ diseases & 11 & 15.7 & 25 & 23.6 & 36 & 20.5 & \\
\hline \multicolumn{8}{|c|}{ Current disease/detected complications } \\
\hline Hypertension & 50 & 71.4 & 84 & 79.3 & 134 & 76.1 & 0.23 \\
\hline Dyslipidemia & 36 & 51.4 & 70 & 66.0 & 106 & 60.2 & 0.05 \\
\hline Musculoskeletal diseases & 15 & 21.4 & 52 & 49.1 & 67 & 38.1 & $<0.01$ \\
\hline Peripheral nerve diseases & 17 & 24.3 & 20 & 18.9 & 37 & 21.0 & 0.39 \\
\hline Coronary artery disease & II & 15.7 & 17 & 16.0 & 28 & 15.9 & 0.95 \\
\hline Renal disease & 8 & 11.4 & 12 & 11.3 & 20 & $1 \mathrm{I} .4$ & 0.98 \\
\hline Liver disease & 7 & 10.0 & 13 & 12.3 & 20 & 11.4 & 0.64 \\
\hline Retinal disease & 7 & 10.0 & 12 & 11.3 & 19 & 10.8 & 0.78 \\
\hline Diabetic foot & I & 1.4 & 1 & 0.9 & 2 & I.I & 0.64 \\
\hline Frailty syndrome & 10 & 14.3 & 23 & 21.7 & 33 & 18.8 & 0.22 \\
\hline
\end{tabular}

first domain was $57.7 \pm 25.6$, while it was $66.1 \pm 30.4$ for the other one. The item with the highest proportion of people giving the correct answer was "Good diet for diabetic patients" (86.4\%), following by "Long term damage of diabetes" (85.8\%), and Reasonable blood pressure levels $(85.8 \%)$.

The mean of attitude and practice score among respondents was $95.8 \pm 13.0$ and $68.1 \pm 16.8$, respectively. All of the participants agreed that "Diabetes affects almost every part of a patients' life" and "Supporting from family and friends are important" (100.0\%). Almost all interviewees actively seek or request medical services to have periodically blood lipid testing (99.4\%). In contrast, there was only $8.5 \%$ of people self-monitoring daily blood glucose (Table 3 ).

Table 4 shows the associations between patients' characteristics and knowledge about diabetes. In the adjusted regression models, knowledge of people aged $\geq 70$ was significantly lower than people aged 60 to 69 . Higher education and longer diabetic duration were positively associated with knowledge. There were significant 
Table 2 Exploratory Factor Analysis for Knowledge About Diabetes

\begin{tabular}{|c|c|c|c|c|}
\hline Items & $\mathbf{n}$ & $\%$ & $\begin{array}{l}\text { Diabetes } \\
\text { Definition and } \\
\text { Management }\end{array}$ & $\begin{array}{l}\text { Targets for } \\
\text { Diabetic } \\
\text { Control }\end{array}$ \\
\hline Good diet for diabetic patients & 152 & 86.4 & 0.49 & \\
\hline Organs are damaged by diabetes & $15 \mid$ & 85.8 & 0.50 & \\
\hline Reasonable blood pressure levels & $15 \mid$ & 85.8 & & 0.66 \\
\hline Reasonable fasting plasma glucose index & 143 & 81.3 & & 0.75 \\
\hline Diabetes definition & 127 & 72.2 & 0.71 & \\
\hline Reasonable blood glucose 2 hours after meal index & 99 & 56.3 & & 0.73 \\
\hline Duration in which glycosylated hemoglobin test can measure & 96 & 54.6 & 0.71 & \\
\hline Reasonable total cholesterol index & 72 & 40.9 & & 0.65 \\
\hline High blood glucose: cause and risk factors & 69 & 39.2 & 0.74 & \\
\hline The benefit of exercise & 59 & 33.5 & 0.46 & \\
\hline The best way to take care of diabetic patients' feet & 57 & 32.4 & 0.40 & \\
\hline Cronbach's alpha & & & 0.67 & 0.64 \\
\hline Mean (band score: 0-100) & & & 57.7 & 66.1 \\
\hline SD & & & 25.6 & 30.4 \\
\hline Ceiling effect (\%) & & & 6.8 & 28.9 \\
\hline Floor effect (\%) & & & I.I & 7.4 \\
\hline
\end{tabular}

Table 3 Attitude and Practice Towards Diabetes Among Participants

\begin{tabular}{|c|c|c|c|c|c|c|c|}
\hline \multirow[t]{2}{*}{ Characteristics } & \multicolumn{2}{|l|}{ Male } & \multicolumn{2}{|c|}{ Female } & \multicolumn{2}{|l|}{ Total } & \multirow[t]{2}{*}{ p-value } \\
\hline & $\mathbf{n}$ & $\%$ & $\mathbf{n}$ & $\%$ & $\mathbf{n}$ & $\%$ & \\
\hline \multicolumn{8}{|l|}{ Attitude towards diabetes } \\
\hline Diabetes affects almost every part of a diabetic persons' life & 70 & 100.0 & 106 & 100.0 & 176 & 100.0 & \\
\hline Supporting from family and friends are important in dealing with diabetes & 70 & 100.0 & 106 & 100.0 & 176 & 100.0 & \\
\hline Costs for diabetic treatment are expensive & 69 & 98.6 & 106 & 100.0 & 175 & 99.4 & 0.40 \\
\hline Missing medicines has bad effects on health & 69 & 98.6 & 103 & 97.2 & 172 & 97.7 & 0.48 \\
\hline $\begin{array}{l}\text { Keeping the blood sugar close to normal can help to prevent the diabetic } \\
\text { complications }\end{array}$ & 68 & 97.1 & 103 & 97.2 & 171 & 97.2 & 0.66 \\
\hline Patients with diabetes should not follow controlled diet & 65 & 92.9 & 99 & 93.4 & 164 & 93.2 & 0.56 \\
\hline Patients with diabetes need regular health check & 66 & 94.3 & 98 & 92.5 & 164 & 93.2 & 0.77 \\
\hline Patients with diabetes should exercise regularly & 65 & 92.9 & 96 & 90.6 & 161 & 91.5 & 0.59 \\
\hline It is important to control weight in diabetic patients & 63 & 90.0 & 96 & 90.6 & 159 & 90.3 & 0.90 \\
\hline \multicolumn{8}{|l|}{ Practice in diabetic treatment and prevention } \\
\hline Actively seek or request medical services to have periodically blood lipid testing & 69 & 98.6 & 106 & 100.0 & 175 & 99.4 & 0.40 \\
\hline Have you stopped smoking since finding out that you have diabetes? & 51 & 72.9 & 105 & 99.1 & 156 & 88.6 & $<0.01$ \\
\hline Change diet after diagnosis & 54 & 77.1 & 90 & 84.9 & 144 & 81.8 & 0.19 \\
\hline Forgot to use medicine & 53 & 75.7 & 88 & 83.0 & $|4|$ & 80.1 & 0.24 \\
\hline Regularly exercise & 56 & 80.0 & 73 & 68.9 & 129 & 73.3 & 0.10 \\
\hline Eyes checking in the last I year & 53 & 75.7 & 73 & 68.9 & 126 & 71.6 & 0.32 \\
\hline Daily blood pressure checking & 31 & 44.3 & 43 & 40.6 & 74 & 42.1 & 0.63 \\
\hline \multirow[t]{2}{*}{ Daily blood glucose checking } & 8 & 11.4 & 7 & 6.6 & 15 & 8.5 & 0.26 \\
\hline & Mean & SD & Mean & SD & Mean & SD & p-value \\
\hline Attitude score (band score: $0-100$ ) & 96 & 13.0 & 95.7 & 13.1 & 95.8 & 13.0 & 0.67 \\
\hline Practice score (band score: $0-100$ ) & 67 & 18.4 & 67 & 15.7 & 68.1 & 16.8 & 0.59 \\
\hline
\end{tabular}


Table 4 Associated Factors with Knowledge About Diabetes

\begin{tabular}{|c|c|c|c|c|}
\hline & \multicolumn{2}{|c|}{ Diabetes Definition and Management } & \multicolumn{2}{|c|}{ Targets for Diabetic Control } \\
\hline & Coef. & $95 \% \mathrm{Cl}$ & Coef. & $95 \% \mathrm{Cl}$ \\
\hline $\begin{array}{l}\text { Age group ( } \geq 70 \text { vs } 60-69 \text { ) } \\
\text { Area (Rural vs urban) }\end{array}$ & $-15.62 * * *$ & $-21.99 ;-9.25$ & $\begin{array}{l}-20.75^{* * *} \\
-20.45\end{array}$ & $\begin{array}{l}-33.05 ;-8.46 \\
-46.17 ; 5.26\end{array}$ \\
\hline $\begin{array}{l}\text { Education (vs Lower than High school) } \\
\text { High school } \\
\text { Higher than High school }\end{array}$ & $\begin{array}{l}16.15^{* * *} \\
31.21 * * *\end{array}$ & $\begin{array}{l}8.66 ; 23.64 \\
23.47 ; 38.96\end{array}$ & $\begin{array}{l}20.36 * * * \\
33.8 I^{* * *}\end{array}$ & $\begin{array}{l}6.02 ; 34.69 \\
18.75 ; 48.87\end{array}$ \\
\hline $\begin{array}{l}\text { Diabetes duration (vs under } 5 \text { years) } \\
5-10 \text { years } \\
\text { Over } 10 \text { years } \\
\text { Frailty condition (Yes vs no) }\end{array}$ & $\begin{array}{l}12.71 * * * \\
13.66 * * * \\
-11.40 * * *\end{array}$ & $\begin{array}{l}3.72 ; 21.69 \\
5.96 ; 21.37 \\
-19.49 ;-3.30\end{array}$ & -13.02 & $-29.09 ; 3.05$ \\
\hline $\begin{array}{l}\text { Current disease/detected complications (Yes vs no) } \\
\text { Renal disease } \\
\text { Coronary artery disease } \\
\text { Peripheral nerve diseases } \\
\text { Hypercholesterolemia } \\
\text { Musculoskeletal disease } \\
\text { Liver disease }\end{array}$ & $\begin{array}{l}-11.83 * * \\
6.60 \\
9.74 * * \\
-16.13 * * *\end{array}$ & $\begin{array}{l}-21.50 ;-2.16 \\
-2.27 ; 15.47 \\
1.95 ; 17.53 \\
-25.89 ;-6.37\end{array}$ & $\begin{array}{l}32.06 * * * \\
16.79 * * * \\
-11.77 * \\
-12.22\end{array}$ & $\begin{array}{l}16.59 ; 47.53 \\
4.41 ; 29.18 \\
-24.81 ; 1.26 \\
-30.25 ; 5.81\end{array}$ \\
\hline
\end{tabular}

Notes: $*^{* *} p<0.01, * * p<0.05, *_{p}<0.1$.

decrements of diabetes definition and management knowledge in comparison with patients having and not having frailty condition $($ Coefficient $=-11.40 ; 95 \% \mathrm{CI}=-19.49$; -3.30). Interviewees having peripheral nerve diseases or dyslipidemia were more likely to score higher in knowledge about targets for diabetic control (Coef. $=32.06$; 95\% $\mathrm{CI}=16.59 ; 47.53$ and Coef. $=16.79 ; 95 \% \mathrm{CI}=4.41$; 29.18, respectively).

Those patients who had higher education reported significantly higher scores in both attitude and practice regarding diabetes. Moreover, compared to patients without peripheral nerve diseases, people with peripheral nerve diseases reported significant increases in attitude toward diabetes (Coef. $=65.65 ; 95 \% \mathrm{CI}=11.14 ; 119.97)$. As for practice in diabetic treatment and prevention, patients in rural areas reported significantly lower scores compared to those living in urban (Coef. $=-13.41 ; 95 \% \mathrm{CI}=-23.53$; -3.29) (Table 5).

\section{Discussion}

Adequate knowledge, attitude, and practice are very important to manage and treat diseases in the elderly. The results of the study contribute to the existing knowledge in the literature, dividing the patients' knowledge into two main groups "Diabetes definition and management" and "Targets for diabetic control". The conversion scores related to patient attitudes were high, but knowledge and practice were only above average. Advanced age, low educational level, rural area, duration of diabetes under 5 years, and co-morbidities were factors negatively related to the elderly outpatients' knowledge, attitudes, and practice.

Olderdiabetes in the current study showed a moderate level of diabetes knowledge. They had a high percentage of correct answers regarding diet, glycemic index, and blood pressure. In contrast, they lacked knowledge about causes and risk factors of DM, taking care of diabetic patients' feet, and benefits of exercise. This is comparable to that found in a study of Binh et al, among a rural population in the Red River Delta region, which showed a very low comprehensive knowledge of diabetes control, with less than $10 \%$ of the population understanding the concept of DM, the diabetic complications and risk factors, and ways to approach prevention and treatment. ${ }^{13,19,20}$ The previous studies in Asia and developing countries revealed that knowledge related to diabetes is poor among people with diabetes. ${ }^{21-25}$ Some research also indicates that knowledge of diabetes is not sufficient among diabetic patients, especially in the elderly. ${ }^{6,26}$ Some other studies reported that diabetic patients had good levels of diabetes-related knowledge. ${ }^{27-29}$ The current study has shown that there are two main knowledge domains that can be used to assess knowledge in the target 
Table 5 Associated Factors with Attitude and Practice Towards Diabetes

\begin{tabular}{|c|c|c|c|c|}
\hline & \multicolumn{2}{|c|}{$\begin{array}{l}\text { Attitude Towards } \\
\text { Diabetes }\end{array}$} & \multicolumn{2}{|c|}{$\begin{array}{l}\text { Practice in Diabetes Treatment and } \\
\text { Prevention }\end{array}$} \\
\hline & Coef. & $95 \% \mathrm{Cl}$ & Coef. & $95 \% \mathrm{Cl}$ \\
\hline $\begin{array}{l}\text { Age group ( } \geq 70 \text { vs } 60-69 \text { ) } \\
\text { Area (Rural vs urban) }\end{array}$ & $-32.29 * *$ & $-62.76 ;-1.82$ & $\begin{array}{l}-3.99 \\
-|3.4| * * *\end{array}$ & $\begin{array}{l}-8.81 ; 0.83 \\
-23.53 ;-3.29\end{array}$ \\
\hline $\begin{array}{l}\text { Education (vs Lower than High school) } \\
\text { High school } \\
\text { Higher than High school } \\
\text { Frailty condition (Yes vs no) }\end{array}$ & $\begin{array}{l}64.47 * * * \\
79.97 * * * \\
-24.85\end{array}$ & $\begin{array}{l}27.08 ; 101.86 \\
31.96 ; 127.98 \\
-55.11 ; 5.41\end{array}$ & $\begin{array}{l}5.34 * \\
11.06 * * *\end{array}$ & $\begin{array}{l}-0.31 ; 10.98 \\
5.23 ; 16.89\end{array}$ \\
\hline $\begin{array}{l}\text { Comorbidity (vs none) } \\
\text { One disease } \\
\text { Two diseases } \\
\text { Three diseases } \\
\text { More than } 3 \text { diseases }\end{array}$ & & & $\begin{array}{l}-0.32 \\
4.68 \\
12.51 * * \\
7.96\end{array}$ & $\begin{array}{l}-9.62 ; 8.99 \\
-5.18 ; 14.54 \\
2.20 ; 22.81 \\
-3.90 ; 19.81\end{array}$ \\
\hline $\begin{array}{l}\text { Current disease/detected complications (Yes vs no) } \\
\text { Coronary artery disease } \\
\text { Retinal disease } \\
\text { Peripheral nerve diseases } \\
\text { Hypercholesterolemia }\end{array}$ & $65.56^{* *}$ & $11.14 ; 119.97$ & $\begin{array}{l}5.26 \\
6.93 \\
-5.18\end{array}$ & $\begin{array}{l}-2.06 ; 12.58 \\
-1.4 I ; 15.26 \\
-I 1.67 ; 1.31\end{array}$ \\
\hline
\end{tabular}

Notes: $* * * p<0.01, * * p<0.05, * p<0.1$.

population. The factor "Diabetes definition and management" may be valuable in future studies. The research discovered that only $8.5 \%$ of participants reported regular selfmonitoring of blood glucose at home. This finding was lower compared to those in the American study among older adults with type 2 diabetes $(40 \%){ }^{30}$ This difference may be explained by the fact that insurance reimbursement for testing supplies is not available in Vietnam. Therefore, the elderly have to pay for blood glucose tests and glucose meters regardless of income. This highlights the need for effective diabetic education programs in the elderly on the prevention of diabetes complications and regular selfmonitoring of blood glucose at home. Financial assistant programs may help diabetic patients increase their frequency of self-monitoring. On the other hand, inadequate knowledge status in patients is also linked to inadequate practice. Elderly patients with diabetes in our study were recruited at the hospital, so they may be more likely to a positive attitude about managing and treating the disease since they are regularly consulted by medical professionals. However, individuals outsides of medical settings may have less knowledge and poorer practices. Previous research revealed that knowledge and practice of foot care in diabetic patients were substandard, and the majority of the respondents (45.7\%) never checked their feet daily. ${ }^{31}$ This raises concerns for the vital needs of regular education regarding foot care and the benefits of exercise for aging diabetic patients in Vietnam. This situation highlighted that there continues to be barriers to treatment adherence and outcomes. The physicians should have methods to help patients to improve their knowledge and practice in routine visits.

The impact of geriatric syndrome, including frailty and co-morbidity conditions, has been important in studies related to the treatment of diabetes in this group. This study also shows that frailty and co-morbidities/DM complications could impair patients' knowledge. ${ }^{32,33}$ The explanation for this may be due to functional and cognitive impairment and dependence to perform the activities of daily living, which can be a barrier to improve knowledge in older diabetic patients. In particular, this finding showed that knowledge of patients aged $\geq 70$ was significantly lower than those aged 60 to 69 . The research results also indicate that the higher the level of education was associated with greater knowledge. $^{21,22,27,34}$ Diabetes is considered a selfmanageable condition, and patients themselves play a vital role in managing their condition. Increasing the effectiveness of self-management support may have a considerable impact on health care. ${ }^{35}$ Among the elderly and especially those with co-morbidities, developing family-based treatment is a viable option to address this problem. 
Further training for elderly diabetic patients and their family members is essential. The assessment of knowledge, attitude, and practice in the study provided evidence for physicians, the hospital leaders and other geriatric departments and hospitals to develop the training programs for elderly diabetic patients to improve the treatment outcomes.

We acknowledge this study has several limitations. First, due to the nature of the cross-sectional design, we could not draw causal relationships between KAP and other factors. Second, this study was conducted in the hospital, so those treated in the hospital may have better KAP; this can lead to overestimation. Further studies should be conducted in communities to improve knowledge regarding diabetes and emphasize lifestyle modifications of older people.

\section{Conclusion}

In conclusion, this study shows relatively good levels of attitude on diabetes mellitus among elderly DM patients in Vietnam. However, the knowledge and practice levels were inadequate. Our results show that diabetes health literacy needs to be improved for better health promotion. The study highlights the essential needs for pragmatic diabetic health literacy, counseling, and education programs in both clinical and community settings as well as home-based treatment dedicated to older diabetic patients. Further researches, like randomized intervention trials, are necessary to improve management and outcomes for this population.

\section{Ethics Approval}

We confirm that this study was conducted in accordance with the Declaration of Helsinki.

\section{Disclosure}

The authors report no other conflicts of interest in this work.

\section{References}

1. Saeedi P, Petersohn I, Salpea P, et al. Global and regional diabetes prevalence estimates for 2019 and projections for 2030 and 2045: results from the International Diabetes Federation Diabetes Atlas, 9th edition. Diabetes Res Clin Pract. 2019;157:107843. doi:10.1016/j. diabres.2019.107843

2. Schram MT, Baan CA, Pouwer F. Depression and quality of life in patients with diabetes: a systematic review from the European Depression in Diabetes (EDID) research consortium. Curr Diabetes Rev. 2009;5(2):112-119. PubMed PMID: PMC2764861. doi:10.2174/ 157339909788166828
3. Seuring T, Archangelidi O, Suhrcke M. The economic costs of Type 2 diabetes: a global systematic review. Pharmacoeconomics. 2015;33 (8):811-831. PubMed PMID: PMC4519633. doi:10.1007/s40273015-0268-9

4. Li Y, Burrows NR, Gregg EW, Albright A, Geiss LS. Declining rates of hospitalization for nontraumatic lower-extremity amputation in the diabetic population aged 40 years or older: U.S., 1988-2008. Diabetes Care. 2012;35(2):273-277. PubMed PMID: 22275440. Pubmed Central PMCID: Pmc3263875. doi:10.2337/dc11-1360

5. Huang ES, Laiteerapong N, Liu JY, John PM, Moffet HH, Karter AJ. Rates of complications and mortality in older diabetes patients: the diabetes and aging study. JAMA Intern Med. 2014;174(2):251-258. PubMed PMID: PMC3950338. doi:10.1001/jamainternmed.2013.12956

6. Borba AKOT, Arruda IKG, Marques APO, Leal MCC, ADS. D. Knowledge and attitude about diabetes self-care of older adults in primary health care [Conhecimento sobre o diabetes e atitude para o autocuidado de idosos na atenção primária à saúde]. Cien Saude Colet. 2019;24(1):125-136.

7. Norris SL, Engelgau MM. Effectiveness of self-management training in type 2 diabetes: a systematic review of randomized controlled trials. Diabetes Care. 2001;24(3):561-87. doi:10.2337/diacare.24.3.561

8. Otero LM, Zanetti ML, Ogrizio MD. Knowledge of diabetic patients about their disease before and after implementing a diabetes education program. Rev Lat Am Enfermagem. 2008;16:231-237. doi:10.1590/S0104-11692008000200010

9. Brewer NT, Chapman GB, Gibbons FX, Gerrard M, McCaul KD, Weinstein ND. Meta-analysis of the relationship between risk perception and health behavior: the example of vaccination. Health Psychol. 2007;26(2):136-145. PubMed PMID: 17385964. doi:10.1037/02786133.26.2.136

10. Mohan D, Raj D, Shanthirani CS, et al. Awareness and knowledge of diabetes in Chennai-the Chennai Urban Rural Epidemiology Study [CURES-9]. J Assoc Physicians India. 2005;53:283-287. PubMed PMID: 15987011.

11. Pham NM, Eggleston K. Diabetes prevalence and risk factors among vietnamese adults: findings from community-based screening programs. Diabetes Care. 2015;38(5):e77-8. PubMed PMID: 25908162. doi:10.2337/dc14-3093

12. Wei Y, Wang H, Li Y, Jiang Z. Predicting population age structures of China, India, and Vietnam by 2030 based on compositional data. PLoS One. 2019;14(4).

13. Binh TQ, Phuong PT, Nhung BT. Knowledge and associated factors towards type 2 diabetes among a rural population in the Red River Delta region, Vietnam. Rural Remote Health. 2015;15(3):3275. PubMed PMID: 26408862.

14. Federation TID. Type 2 diabetes: the International Diabetes Federation. Available from: https://www.idf.org/aboutdiabetes/type2-diabetes.html. Accessed October 3, 2020.

15. Federation TID. IDF Clinical Practice Recommendations for Managing Type 2 Diabetes in Primary Care. Brussels, Belgium: International Diabetes Federation; 2017.

16. Anderson RM, Fitzgerald JT, Funnell MM, Gruppen LD. The third version of the diabetes attitude scale. Diabetes Care. 1998;21 (9):1403-1407. PubMed PMID: 9727884. doi:10.2337/diacare.21. 9.1403

17. Fitzgerald JT, Funnell MM, Hess GE, et al. The reliability and validity of a brief diabetes knowledge test. Diabetes Care. 1998;21 (5):706-710. PubMed PMID: 9589228. doi:10.2337/diacare.21.5.706

18. Vu HTT, Nguyen TX, Nguyen TN. Prevalence of frailty and its associated factors in older hospitalised patients in Vietnam. BMC Geriatr. 2017;17(1):216. doi:10.1186/s12877-017-0609-y

19. Kiberenge MW, Ndegwa ZM, Njenga EW, Muchemi EW. Knowledge, attitude and practices related to diabetes among community members in four provinces in Kenya: a cross-sectional study. Pan Afr Med J. 2010;7:2. PubMed PMID: 21918691. Pubmed Central PMCID: Pmc3172632. 
20. Masood I, Saleem A, Hassan A, Umm EK, Zia A, Khan AT. Evaluation of diabetes awareness among general population of Bahawalpur, Pakistan. Prim Care Diabetes. 2016;10(1):3-9. PubMed PMID: 26137919. doi:10.1016/j.pcd.2015.06.004

21. Abbasi YF, See OG, Ping NY, Balasubramanian GP, Hoon YC. Diabetes knowledge, attitude, and practice among type 2 diabetes mellitus patients in Kuala Muda District, Malaysia - a cross-sectional study. Diabetes Metab Syndr Obes. 2018;12(6):1057-1063. doi:10.1016/j.dsx.2018.06.025

22. Gautam A, Bhatta DN, Aryal UR. Diabetes related health knowledge, attitude and practice among diabetic patients in Nepal. BMC Endocr Disord. 2015;15(1). doi:10.1186/s12902-015-0021-6

23. Hussain R, Rajesh B, Giridhar A, et al. Knowledge and awareness about diabetes mellitus and diabetic retinopathy in suburban population of a South Indian state and its practice among the patients with diabetes mellitus: A population-based study. Indian J Ophthalmol. 2016;64(4):272-276. doi:10.4103/0301-4738.182937

24. Islam FMA, Chakrabarti R, Dirani M, et al. Knowledge, attitudes and practice of diabetes in Rural Bangladesh: the Bangladesh population based diabetes and eye study (BPDES). PLoS One. 2014;9(10): e110368. doi:10.1371/journal.pone.0110368

25. Hawal NP, Kambar S, Patil S. Knowledge, attitude and behaviour regarding self-care practices among type 2 diabetes mellitus patients residing in an urban area of South India. Int Multidisciplinary Res J. 2012;2(12):31-35

26. Upadhyay D, Palaian S, Shankar PR, Mishra P. Knowledge, attitude and practice about diabetes among diabetes patients in Western Nepal; 2008.

27. Zibran MA. Determinants of knowledge, attitude and practice in patients with both type 2 diabetes and chronic kidney disease in Fiji. F1000Res. 2019;8(239). doi:10.12688/f1000research.18188.3

28. Saleh F, Mumu SJ, Ara F, Begum HA. Knowledge and self-care practices regarding diabetes among newly diagnosed type 2 diabetics in Bangladesh: a cross-sectional study. BMC Public Health. 2012;12 (1):1112. doi: $10.1186 / 1471-2458-12-1112$
29. Gul N. Knowledge, attitudes and practices of type 2 diabetic patients. J Ayub Med Coll Abbottabad. 2010;22(3):128-131.

30. Skelly AH, Arcury TA, Snively BM, et al. Self-monitoring of blood glucose in a multiethnic population of rural older adults with diabetes. Diabetes Educ. 2005;31(1):84-90. PubMed PMID: 15779249. Pubmed Central PMCID: Pmc1630682. doi:10.1177/ 0145721704273229

31. Seid A, Tsige Y. Knowledge, practice, and barriers of foot care among diabetic patients attending Felege Hiwot Referral Hospital, Bahir Dar, Northwest Ethiopia. Adv Nurs. 2015;2015:9. doi:10.1155/ 2015/934623

32. Degano IR, Subirana I, Fusco D, et al. Percutaneous coronary intervention reduces mortality in myocardial infarction patients with comorbidities: implications for elderly patients with diabetes or kidney disease. Int $J$ Cardiol. 2017;249:83-89. PubMed PMID: 29121766. doi:10.1016/j.ijcard.2017.07.054

33. Khalaf FR, Fahmy HM, Ibrahim AK, et al. Does a diabetic retinopathy educational program raise awareness among elderly diabetic patients? Diabetes Metab Syndr Obes. 2019;12:1867-1875. PubMed PMID: 31571961. Pubmed Central PMCID: PMC6759836. doi:10.2147/DMSO.S208072

34. Devarapalli P, Mehdiratta N, Mamillapalli S, Akella S. Patient education in management of diabetes with medical comorbidities: an interventional study in South-eastern India. Int J Sci Rep. 2019;5 (1):24-28.

35. Ishak NH, Mohd Yusoff SS, Rahman RA, Kadir AA. Diabetes self-care and its associated factors among elderly diabetes in primary care. J Taibah Univ Med Sci. 2017;12(6):504-511. PubMed PMID: 31435286. Pubmed Central PMCID: PMC6694907.

\section{Publish your work in this journal}

Diabetes, Metabolic Syndrome and Obesity: Targets and Therapy is an international, peer-reviewed open-access journal committed to the rapid publication of the latest laboratory and clinical findings in the fields of diabetes, metabolic syndrome and obesity research. Original research, review, case reports, hypothesis formation, expert opinion and commentaries are all considered for publication. The manuscript management system is completely online and includes a very quick and fair peer-review system, which is all easy to use. Visit http://www.dovepress.com/testimonials.php to read real quotes from published authors. 